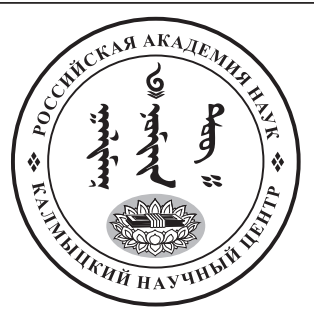

Published in the Russian Federation

Oriental Studies (Previous Name: Bulletin of the Kalmyk Institute

for Humanities of the Russian Academy of Sciences)

Has been issued as a journal since 2008

ISSN: 2619-0990; E-ISSN: 2619-1008

Vol. 13, Is. 4, pp. 1167-1176, 2020

DOI: $10.22162 / 2619-0990-2020-50-4-1167-1176$

Journal homepage: https://kigiran.elpub.ru

УДК 398.22:821.512.36

DOI: 10.22162/2619-0990-2020-50-4-1167-1176

\title{
Функции змеи в обрядовом фольклоре монгольских народов
}

\section{Людмила Санжибоевна Дампилова ${ }^{1}$, Екатерина Владимировна Сундуева}

${ }^{1}$ Институт монголоведения, буддологии и тибетологии СО РАН (д. 6, ул. Сахьяновой, 670047 Улан-Удэ, Российская Федерация)

доктор филологических наук, главный научный сотрудник

iD)0000-0003-0917-5432. E-mail: dampilova_luda@rambler.ru

${ }^{2}$ Институт монголоведения, буддологии и тибетологии СО РАН (д. 6, ул. Сахьяновой, 670047 Улан-Удэ, Российская Федерация), доктор филологических наук, главный научный сотрудник

iD 0000-0003-2299-3384. E-mail: sundueva@mail.ru

\author{
(C) КалмНЦ РАН, 2020 \\ (С) Дампилова Л. С., Сундуева Е. В., 2020
}

Аннотация. Введение. В мифологии народов мира образ змеи как один из самых изучаемых персонажей имеет разные интерпретации. В фольклоре тюрко-монгольских народов также он изучен достаточно широко. В данной статье мы впервые обращаемся к образу змеи как табуированному сакральному персонажу в обрядовом фольклоре монгольских народов. Цель статьи - выявление символической функции змеи в обрядовом фольклоре монгольских народов, установление положительных и отрицательных коннотаций. Материалы и методы. Основным методом исследования является компаративистский анализ образа змеи как семиотического знака. Междисциплинарный анализ этнографических и фольклорных материалов, также сравнение с тюркскими обрядовыми действами расширяют границы выявления семантики образа змеи. Результаты. Змея в шаманской мифологии монгольских народов выступает в ипостаси потустороннего духа, тесно связанного с шаманом. Изображения змей на наскальных рисунках, петроглифах, шаманских онгонах, костюмах подчеркивают их сакральную функцию. В шаманской практике образ змеи может использоваться с защитной функцией в виде трости или кнута. Развитый символ змеи в виде жгутов является коннотацией ее магических оборотнических способностей. Эта функция медиатора между мирами дает змее возможность одновременно выполнять и функцию защитной силы. Функции змеи в обрядах взаимозаменяемы и дополняют друг друга. В шаманских текстах монгольских народов устойчиво повторяется основная функция змеи как перевозчика между мирами, также тесно связанная с ее оборотническими способностями. Bыводы. В итоге исследования определены функции змеи в шаманских обрядовых действах монгольских народов с положительной коннотацией как помощника, посредника, перевозчика и посланника с иного мира для связи между мирами. 
Выявлены перекодировка образа змеи в разных семиотических системах, взаимосвязанность и взаимозаменяемость функций сакральной рептилии.

Ключевые слова: сакральная функция, ритуал, шаманизм, защитник, посредник, медиатор, перевозчик

Благодарность: Работа выполнена при поддержке РФФИ-МОКНМ в рамках научно-исследовательского проекта № 18-512-94003 «Сохранность и трансформация фольклорных и этнокультурных традиций бурят России, Монголии и Китая». Материалы статьи апробированы на Международной научной онлайн-конференции «Монголоведение в начале XXI в.: современное состояние и перспективы развития - II», проведенной при финансовой поддержке РФФИ (проект № 20-09-22004) и частичной поддержке гранта Правительства РФ (№ 075-15-20191879).

Для цитирования: Дампилова Л. С., Сундуева Е. В. Функции змеи в обрядовом фольклоре монгольских народов // Oriental Studies. 2020. Т. 13. № 4. С. 1167-1176. DOI: 10.22162/26190990-2020-50-4-1167-1176

UDC 398.22:821.512.36

DOI: $10.22162 / 2619-0990-2020-50-4-1167-1176$

\section{Ceremonial Folklore of Mongolic Peoples: Functions of the Snake Revisited}

\section{Liudmila S. Dampilova1, Ekaterina V. Sundueva ${ }^{2}$}

${ }^{1}$ Institute for Mongolian, Buddhist and Tibetan Studies, Siberian Branch of the RAS (6, Sakhyanova St., Ulan-Ude 670047, Russian Federation)

Dr. Sc. (Philology), Chief Research Associate

iD 0000-0003-0917-5432. E-mail: dampilova_luda@rambler.ru

${ }^{2}$ Institute for Mongolian, Buddhist and Tibetan Studies, Siberian Branch of the RAS (6, Sakhyanova

St., Ulan-Ude 670047, Russian Federation)

Dr. Sc. (Philology), Chief Research Associate

iD 0000-0003-2299-3384. E-mail: sundueva@mail.ru

(C) KalmSC RAS, 2020

(C) Dampilova L. S., Sundueva E. V., 2020

Abstract. Introduction. In mythologies of the world, the image of the snake ranks among the most studied characters and has various interpretations. In folklore of Turko-Mongols, it has also been a subject of multiple analyses. Still, the article makes a first attempt at revealing the image of the snake as a taboo sacred character in ritual folklore of the Mongolic peoples. Goals. The paper primarily seeks to identify functions of the snake therein, delineate the symbolic framework, reveal positive and negative connotations. Materials and Methods. The main research method employed is that of comparative analysis instrumental in examining the image of the snake as a semiotic sign. Interdisciplinary analysis of ethnographic and folklore materials, as well as comparisons to Turkic ritual actions, expand the boundaries of identifying the semantics of the image. Results. The snake in shamanic mythology of the Mongolic peoples appears in the hypostasis of the otherworldly Spirit closely associated with the shaman. Images of snakes in cave drawings, petroglyphs, shamanic ongons (sanctuaries), and costumes emphasize their sacred function. In shamanic practice, a snake image can be used as a protective element in the form of a walking-stick or whip. Symbolically, a snake in the form of straps implies a connotation of the animal's magical abilities. The role of a mediator between worlds allows the snake simultaneously performing the function of a protective force. Functions of the snake in rites are interchangeable and complement each other. Shamanic texts of the Mongolic peoples consistently mention the main function of the snake is that of a carrier between worlds, which is closely related to 
its transforming abilities. Conclusions. The study resumes the snake in shamanic ritual actions of the Mongolic peoples — with positive connotations - functions as an assistant, intermediary, carrier, and envoy from another world that provides communication between realms. It also reveals patterns of transcoding the snake image in different semiotic systems, interconnectedness and interchangeability of sacral reptile functions.

Keywords: sacral function, ritual, shamanism, defender, intermediary, mediator, carrier

Acknowledgements: The reported study was funded by RFBR, project no. 18-512-94003 'Buryats of Russia, Mongolia and China: Preservation and Transformation of Folklore and Ethnocultural Traditions'. The article was presented at the International scientific online conference 'Mongolian Studies at the Beginning of the $21^{\text {st }}$ century: Current State and Development Prospects - II' funded by RFBR (project no. 20-09-22004) and Government of the Russian Federation (grant no. 075-15-2019-1879). For citation: Dampilova L. S., Sundueva E. V. Ceremonial Folklore of Mongolic Peoples: Functions of the Snake Revisited. Oriental Studies. 2020. Vol. 13(4): 1167-1176. (In Russ.) DOI: 10.22162/2619-0990-2020-50-4-1167-1176

\section{है}

\section{Введение}

Образ змеи, имеющий многочисленные интерпретации в мифологии разных народов с древних времен, достаточно распространен в традиции тюрко-монгольских народов. В обрядовом фольклоре особое внимание уделяется образу змеи как табуированному сакральному персонажу. Актуальным представляется проследить функции змеи в ритуально-обрядовой практике монгольских народов, исходя из утверждения, что «змеи — основообразующий персонаж в модели мира» [Цивьян 1984: 85]. В связи с тем, что нами были исследованы взаимосвязь мифологических персонажей змей, лусудов (духи воды) и лусов (небесных драконов) в монгольской мифологии, в данной статье назрела необходимость отдельно изучить функции змеи в обрядовом фольклоре монгольских народов. Целью статьи является выявление символических функций змеи в обрядовом фольклоре монгольских народов, схожие и специфические функции в разных локальных традициях.

\section{Материалы и методы}

Материалами исследования являются современные полевые записи авторов в сравнении с более ранними источниками по данной теме. Для выявления устойчивости мифологических функций образа змеи как семиотического знака основным является метод компаративистского анализа бурятских, дархатских, ойратских, урянхайских шаманских традиций. Не менее важным в исследовании представляется междисци- плинарный анализ этнографических и фольклорных материалов, расширяющий границы исследовательского поля.

\section{Сакральная функция змеи}

В традиции монгольских народов существовал запрет на произношение имен священных животных как тотемов, к ним относили и змей со множеством табуированных имен. Змея могла быть завуалирована как вид обычного насекомого - червя (хорхой), но особо примечательно, что во всей монгольской традиции обращались к змеям как к самым уважаемым божествам с помощью слова хайрхан. Свои определенные тотемные первопредки-животные были У разных племен и родов, и ареал их распространения - локальный. Хотя и змеи были тотемами определенных родов (например, бурятский хурдутский род змею считает своим первопредком), обращение хайрхан подчеркивает, что змеи относились к общим божествам, которых чтили все монгольские племена.

Изображения змей на петроглифах Центральной Азии и Южной Сибири, датируемых эпохой неолита и бронзы, доказывают древние корни культа змей. А. П. Окладников, анализируя петроглифы Западной Монголии, отмечает, что «змея у древних обитателей Гоби вызывала не только страх, но и чувство преклонения» [Окладников 1980: 5].

В бурятских мифах устойчиво упоминаются змеи как хозяева местности, царь подземных золотых богатств, и им посвя- 
щались специальные тайлганы. По полевым исследованиям Б. 3. Нанзатова и М. М. Содномпиловой, в Иркутской области есть «гора Тураг, где, по представлениям бурят, обитает владыка змей - Могой-хан. Гора знаменита тем, что в ее пределах собираются на зимовку в Покров день (14-15 октября) огромное количество ядовитых змей - гадюк. Культ змей, развитый у местных бурят буровского рода, в прошлом, вероятно, представлял собой компонент общего для бурят культа змей... Интересно, что до сих пор в Байтоге Иркутской области проживает единственный на всю округу шаман, потомственный отправитель культа змей» [Нанзатов, Содномпилова 2005: 55].

В следующем описании обряда жертвоприношения змеиному царю Алтан-толи и его жене Алташа-хатун семиотически выделены змеиные черты, для жертвы выбирается только пестрая овца, и в этом выборе подчеркивается пестрота змеи. Так же значимо, что «при этом обряде вместе с костями сжигают на жертвеннике и часть мяса, свернутого и перевязанного в нескольких местах четырехцветными шелковинами в виде змеи» [Хангалов 2004: 269]. Итак, в бурятском обрядовом фольклоре сохранился мифологический образ не змеи, а змея в мужском роде, являющегося в данном случае владыкой змей. В мифологии монгольских народов наиболее обозначен змей в паре со своей хозяйкой именно как царь подземных сокровищ, золота. Упоминание змей в паре, как принято в пантеоне божеств, еще раз подчеркивает их божественную сакральную функцию.

Многочисленные очертания змей на шаманских онгонах и костюмах также подчеркивают их сакральную функцию. Змеи были изображены на онгонах с разными функциями. У бурят существовали многочисленные онгоны в виде самодельных вещей или рисунков как духи-обереги. На картине «Онгон Усан хад» ('Онгоны водной стихии') изображены озеро с рыбами и байкальской нерпой, еще одно озеро с лягушками, змеями и ящерицами [Балдаев. ЦВРК ИМБТ СО $\mathrm{PAH}$.

В шаманской картине мира обязательным атрибутом водного мира являются отдельно прорисованные и всегда упоминаемые в призываниях сакральные рептилии лягушки и змеи: Нарин могой ильбимнай
/ Намтар баха унаамнай 'Тонкая змея волшебство наше, / Приземистая лягушка - конь мой ${ }^{1}$ [Ксенофонтов. Якутский филиал СО РАН. Ф. 4. Оп. 1. Ед. хр. 52а. Л. 160]. Стоит отметить, что образ лягушки в мифологии монгольских народов почти не проявлен, она упоминается только в паре со змеей. В этом примере примечательно, что функцией змеи отмечается именно ее волшебная оборотническая способность, что связывает ее с шаманской способностью перевоплощения.

Как у бурятских, так и других монгольских шаманов одним из духов, в кого они могли перевоплощаться, были змеи. Онгон «Зуруктун» ('Нарисованный') представлял собой картину на лоскуте ткани: «Двадцать семь персон рогатых (все потомки девяти шаманов): девять из них слепы, девять хромы и девять пахоруки. Тут же изображаются змеи, верблюды, стрекозы, словом, изображаются разные животные как хубилганы этих шаманов» [Затопляев 1890: 9]. Хубилганом называют перерожденца шамана, но здесь, скорее всего, имеется в виду его перевоплощение. По шаманской мифологии, хромыми и слепыми изображались духи восточного темного цикла, их магические способности были намного выше других, и они могли перевоплотиться в разных зверей, в основном в тотемных предков. Итак, змеи как сакральные существа в шаманской мифологии выступают в роли хозяев местности, тотемных первопредков, особенно обозначены как духи для перевоплощений шамана. Их гендерное отношение четко не обозначено, скорее, они выступают в мужской ипостаси.

\section{Функция защитной силы}

Змея в шаманской мифологии монгольских народов имеет разные взаимодополняющие функции. В вербальных материалах наиболее часто змея, не являясь самостоятельным персонажем, считается атрибутом шамана в виде неживых вещественных предметов - символических кнутов, поводьев. Семиотический статус змеи таков, что может подразумеваться под предметом и сам персонаж как действующий герой. В монгольских и бурятских песнопениях наиболее часто используется формула: $\mathrm{Ha}$ -

1 Подстрочные переводы здесь и далее Е. В. Сундуевой. 
рин могой минаамни, бүдүҮн могой унаамни 'Тонкая змея - плеть моя, толстая змея конь мой' [Манжигеев 1978: 60]. Трафаретная формула в первую очередь подчеркивает, что в обрядовом действе шаман в измененном состоянии сознания совершает переход между мирами, используя змею и как коня, и как кнут. По контексту можно определить, что под змеиным кнутом может иногда подразумеваться и перевозчик между мирами.

Кнут в обрядовом событии имеет свое символическое значение. Кнуты и бичи как обрядовые священные инструменты изготавливались из определенных предметов, имеющих защитные силы. Так, например, по сведениям Ц. Жамцарано, шаманы делали бич из тамариска (бур. сухай), который считается священным деревом (онгон модон) и охраняет от удара молнии [Жамцарано. АВ ИВР РАН. Ф. 62. Оп. 1. Л. 19].

Для усиления сакральной силы предмета к тамарисковым, сандаловым кнутам прибавляются еще и мифологические составляющие в виде змеиных головок. Тогда к защитной функции дополнительно прибавляется мистическая магическая сила трости шамана. Помимо характерных для бурятского шаманизма символических вербальных упоминаний, можно отметить сохранившиеся в архивных записях сведения, что змеиная трость (бур. могой һорьбо) использовалась во время обряда как практическая защита и символ магической силы [Балдаев 1942].

Трость в мировой мифологии с древнейших времен считается сакральным предметом, а тут трость со змеиной головкой играет роль универсального посредника между мирами, и посох воспринимается как «живой» мифологический персонаж. Итак, в шаманской практике трости и кнуты в виде змеи могут использоваться с функцией защиты и магической силы. Хотя в статье обозначены раздельно основные функции змеи, все функции змеи между собой взаимосвязаны.

\section{Функция медиатора между мирами}

Как по современным полевым исследованиям, так и архивным записям выявляется, что у монгольских шаманов змея обязательный атрибут обрядовых действ. Шаман может иметь змею в качестве своего постоянного связного между мирами.
В современных полевых исследованиях по Монголии, где особо распространены бурятские шаманские практики, нас привлекли новшества: помимо традиционных змееподобных ленточек по спине шаманского костюма, к рукавам костюма пришиты тринадцать сплетенных веревочек в виде одной большой и двенадцати маленьких змей. По сведениям информанта, змеи служат шаману для получения информации с иного мира [Цырма 2012]. Таким образом, змеи являются связующим звеном с духами, и здесь особое значение имеет глаз змеи, следящий за всеми, наблюдающий как всевидящее око, проникающий в прошлое и будущее. Защитные, оберегающие и оборотнические функции змеи тесно связаны с религиозными представлениями тюрко-монгольских народов о всевидящем и всезнающем змее.

Многочисленные атрибуты для исполнения обрядов имеют символическое значение. У каждого бурятского шамана разнообразный набор предметов: шкурки ежа, змеи, когти, клыки разных животных. По рассказу информанта, «к поясу шаманы подвешивали клыки кабана, соболя, колонка, куницы и когти орла. В обряде лечения используются как лекарственные средства шкурки змеи» [Цыренов 2012]. Набор предметов, как правило, зависел и от тотемного первопредка, исполняющего обряд шамана.

В полевых исследованиях по Монголии наше внимание привлекло у дархатских шаманов использование во время обряда жгутов, похожих на змей. К обязательному для всех шаманов символическому атрибуту - зеркалу (монг. толи) у дархатской шаманки подвешены разноцветные ленточки (монг. манжи), которые помогают шаману увидеть будущее или выяснить причину болезни. По полевым записям Г. Д. Санжеева, сделанным в 1930-х гг. у дархатских шаманов, «эти жгуты служат для исполнения обряда зальбарха (просить духов о ниспослании счастливой жизни)» [Санжеев 1931: 60].

Обращаясь к разным символическим функциям жгутов манжи как змей, отметим, что особый интерес представляют сведения информанта Б. Доржготова, записавшего у современного дархатского шамана ('заарин бөө') Б. Амгалана отрывок из призывания: 
Наян найман манжиганда нь

Намтар түухэнь өвлөөтэй,

Найман хар могойндонь

Хараал жагтань өвлөөтэй.
В восьмидесяти восьми его жгутах

Хранится его история,

В восьми его черных змеях

Хранятся его заклинания.

[Доржготов 2012].

Примечательно, что в данном тексте в параллельных стихотворных конструкциях упоминаются манжи и змеи с одинаковыми функциями. Восемьдесят восемь змей шамана, знающие его родословную и помогающие ему, являются его магической связью с предками и силой. По бинарной системе противопоставляются им восемь черных змей, и они нагружены по цветовому коду отрицательной функцией, показывая и темные силы шамана. Следует подчеркнуть, что в обрядовом фольклоре змеи в основном обладают положительной коннотацией, их отрицательная роль почти не проявлена. В фольклорных же текстах одним из самых распространенных мотивов является мотив борьбы белой и черной змей. Например, демон Дырь видит во сне выходящими из своих ушей змей, причем белая змея - это душа Гесера, а черная - душа самого демона [Потанин 1883: 26].

Наконец, как свидетельство важной содержательной особенности распространения символики змей в виде манжи у тюрко-монгольских народов для нашего исследования значимы записи Г. Н. Потанина. В них упоминаются следующие факты: жгуты-змеи пришиты к онгонам-куклам, хозяин юрты называет их маньяк; у каждого народа свое определенное число защищающих змей; у теленгутов шесть змей на онгонах: «верхние концы жгутиков тупо заостренные, слегка напоминающие головки змеи; нижние концы имеют вид кисточек, сделанных из цветных ленточек»; у урянхайцев девять жгутиков толщиной в гусиное перо, они их называют манджак-сабынь [Потанин 1883: 95, 97, 100, 102, 103 ].

Г. Н. Потанин отмечает одинаковые шаманские традиции урянхайцев и дархатов Косоголья. Возможно, здесь один ареал распространения символики змей в виде манжси. Таким образом, в тюрко-монгольском шаманизме образ змеи в виде жгутов является коннотацией магических оборотнических способностей. И эта функция медиатора между мирами дает змее возмож- ность одновременно выполнять и функцию защитной силы.

Семиотический статус змеи меняется в зависимости от локальных традиций и каждой отдельной шаманской истории. Так, змея может связывать шамана с магическими существами. По рассказам дархатской шаманки, «вчера приползла змея, серо-пестрая (бор эреэн), вон в том углу лежала. Она осуществляет связь с лусудами» [Насанцэцэг 2011]. В монгольской шаманской мифологии лусы - хозяева подводного пространства, «змеи, лусы и луу имеют общие змееподобные визуальные черты, тесно связаны между собой и с водной стихией» [Дампилова 2017: 187].

Констатируем, что образ змеи в виде манжи распространен в дархатском шаманизме и у ближайших тюркских народов. Манжи у дархатов в Монголии продолжают и сегодня использоваться с функцией защиты, дарителя благополучия, медиатора между мирами, некоторая трансформация функций зависит от вида обряда. Примечательно, что в бурятской традиции образ змеи в виде манжи ни в полевых исследованиях, ни архивных источниках не встречается. Итак, основной сакральной функцией змеи как магического существа с оборотническими способностями является функция связующего звена как с духами потустороннего мира, так и божествами разного ранга.

Функция перевозчика между мирами

Функции змеи в обрядах взаимозаменяемы и взаимно дополняют друг друга. В шаманских текстах монгольских народов устойчиво повторяется функция змеи как перевозчика между мирами, хотя перевозчиками могут быть и разные животные. В призывании дархатской (шарнут) шаманки Буд ('Буд удаганы тамлага') могучая змея выполняет указанную функцию: 'C устрашающе красивыми телами / C огромными змеями-перевозчиками' Аюулт сайхан бэетэнгууд / Аварга могой унаатангууд [Ринчен 2013: 151]. 
Особенно часто встречается огненный, красный цвет змеи, подчеркивающий магическую силу существа иного мира. В шаманской мифологии символическое значение имеют размеры, числовая и цветовая символика змеи.

В призывании урянхайского шамана атрибутами Черного Буман тэнгри (Хap Буyман тэнгэр минь) упоминаются бешеный волк как перевозчик и огненно-желто-пестрая змея как кнут: Галзуу чонон хүлэгт / Гал могой ташуурт 'Бешеный волк - перевозчик, / Огненная змея - кнут' [Ринчен 2013: 162]. Огненно-пестрый цвет змеи является кодировкой как ее волшебных способностей, так и мощной темной защитной силы, ибо змеи такого цвета служат божествам черного восточного цикла. В призываниях зачастую змея может выступать и как кнут, и как перевозчик между мирами, что еще раз подчеркивает многофункциональность змеи.

Функция змеи может меняться и определяться контекстом обрядового события, и немалую роль здесь играют пространственные и временные коды. Возможно, мотив защиты и перевоплощения взаимосвязаны и восходят к более архаической мифологической семантике. В обрядовом фольклоре монгольских народов особое значение имеет выявленное В. Я. Проппом заключение, что змеи своими историческими корнями восходят к представлению о ней как о священном животном - тотеме [Пропп 2009: 191-193].

Функции чудодейственной силы, всезнания, мстящей души

Как известно, современные исследователи «в мифах и сказках пытаются идентифицировать остаточные следы ритуалов» [Вульф 2008: 167]. С этой точки зрения мифологическая функция змеи, выявленная в обрядовой практике, имеет разные коннотации в фольклорных жанрах. В устных рассказах бурят, калмыков и монголов сохранились многочисленные поверья, приметы, в которых выявляются функции чудодейственной силы змеи в лечебной практике. Лечебное свойство имеют кожа, мясо змеи, более ранний мифологический мотив - лечебные свойства рожек змеи. «Змеи линяют; сброшенную кожу (зулмадхан) буряты берут, потому что приписывают ей лекар- ственную силу... Мясо белой змеи также советуют высушить и хранить, потому что оно считается целебным от разных болезней» [Хангалов 2004: 55].

В калмыцкой традиции выделяются белые рогатые змеи, как бы посланные в дар предками: «С помощью змеиных рогов хорошо излечиваются разные опухоли женской груди, а также опухоль коровьего вымени, потертости от седла на теле коня» [Басангова 2019: 136].

Примечательно, что мотив чудодейственной силы змеи, ее кожи, мяса или рогов, мотив получения дара костоправа от змеи в монгольском фольклоре обнаруживают точные совпадения с фольклором тюркских народов [Бурнаков 2020].

Функция чудодейственных свойств змеиных рожек имеет, таким образом, международный характер. То же можно сказать о функции всезнания змеи. Человек получает волшебный дар знания от змеи, и одновременно ему достается дар предвидения. В фольклоре монгольских народов развит мотив как съедания мяса змеи, облизывания ее языка и получения дара знания языка змеи, так и получения подарка от змеи в виде знания семидесяти семи языков животных. Отголоском мифологических рассказов о змеином языке у бурят осталась примета, что при тяжебных делах нужно иметь при себе змеиный язык, тогда точно выиграешь тяжбу [Хангалов 2004: 55].

В фольклоре монгольских народов распространена функция змеи как мстящей души. Общеизвестный мотив «проклятой змеиной крови», контаминируясь с образом огненного крылатого змея, предвещавшего беду, в фольклоре монгольских народов создает зловещий образ змеи как реальной, так и мифологической.

Образ огненного змея близок образам эпических гигантских змей с отрицательной коннотацией. Если в обрядовом фольклоре змеи - чаще мифологические существа, то в устных рассказах они чаще обозначены как змеи реального мира. Исследуя образ змеи в традиционной культуре бурят, А. А. Бадмаев приходит к выводу о достаточно сложном и амбивалентном характере змеи [Бадмаев 2019: 124]. Итак, чтобы дополнить сведения о функциях змеи в обрядовом фольклоре, нами кратко охарактеризованы выявленные, приписываемые рептилии, функции 
чудодейственной лечащей силы, знания языков животных, дара предвидения, мстящей души, отмечен противоречивый характер змеи в устных рассказах. Образ змеи в эпических и сказочных текстах достаточно изучен в монголоведении.

\section{Заключение}

В гендерном отношении в обрядовом фольклоре змея наиболее четко проявлена в мужской ипостаси как потусторонний дух и связующее звено между мирами. И в этом случае в пространственных кодах шаманских ритуалов змея чаще локализуются на небесах. Змея как хозяин местности может быть тоже с небесной локацией, как и принято в шаманской мифологии. Змея как хтоническое существо в редких обрядовых событиях появляется вместе хозяином подводного царства и локализуется в подземном пространстве. Помимо пространственной, гендерной позиции, как выявлено в ходе

\section{Полевые материалы авторов}

Доржготов 2012 - Б. Доржготов, 1961 г. рожд., дархат. Запись Л. С. Дампиловой, 2012 г., с. Ханх, Хубсугульский аймак, Монголия.

Насанцэцэг 2011 - Насанцэцэг, 1978 г. рожд., дархатка, шаманка. Запись Л. С. Дампиловой, 2011 г., с. Цаган-Ур, Хубсугульский аймак, Монголия.

Цыренов 2012 - Цыренов С. Д., 1938 г. рожд., шошолок, пастух. Запись Л. С. Дампиловой, 2012 г., с. Санага, Закаменский район, Республика Бурятия.

Цырма 2012 - Цырма, 50 лет, хори-бурятка, хуасай, шаманка. Запись Л. С. Дампиловой, 2012 г., с. Ханх, Хубсугульский аймак, Монголия.

\section{Источники}

Балдаев. ЦВРК ИМБТ СО РАН - Балдаев С. П.

Онгоны бурят // Центр восточных рукописей и ксилографов Института монголоведения, буддологии и тибетологии СО РАН (ЦВРК ИМБТ СО РАН). Ф. 36. Оп. 1. Д. 1187.

Балдаев 1942 - Балдаев С. П. Зураг Боро Шарга. Трости шаманов. 1942 г. // ЦВРК ИМБТ СО РАН. Ф. 36. Оп. 1. Д. 1046.

\section{Sources}

Baldaev S. P. Ongons of the Buryats. At: Center for Oriental Manuscripts and Xylographs, Institute анализа текстов, символическое значение имеют цветовые и числовые коды.

Образ змеи-покровителя в мифологических воззрениях имеет разные коннотации. В ходе анализа текстов выявлено, что змея как символ волшебной, магической силы сопровождает шамана, дает дар провидения. Определены функции змеи в шаманских обрядах как помощника, посредника, перевозчика и посланника из иного мира для связи с реальным миром. Особо отмечены защищающие, оберегающие функции змеи. Также приходим к выводу, что функции змеи в обрядовом фольклоре монгольских народов тесно взаимосвязаны. Выявлена перекодировка образа змеи в разных семиотических системах, хотя зачастую змея выполняет одновременно несколько функций в одном и том же обряде. Установлены отрицательные и положительные функции змеи в устных рассказах.

\section{Authors' Field Data}

Informant: B. Dorzhgotov, b. 1961, ethnic Darkhad (male). Rec. by L. Dampilova in 2012 (Khankh, Khövsgöl Province, Mongolia). (In Mong.)

Informant: Nasantsetseg, b. 1978, ethnic Darkhad (female), shaman. Rec. by L. Dampilova in 2011. (Tsagaan-Üür, Khövsgöl Province, Mongolia). (In Mong.)

Informant: Tsyrenov S. D., b. 1938, ethnic Buryat (male), Shosholog clan, shepherd. Rec. by L. Dampilova in 2012. (Sanaga, Zakamensky District, Republic of Buryatia, Russia). (In Bur.) Informant: Tsyrma, 50 y.o., ethnic Khori Buryat (female), Khuasay clan, shaman. Rec. by L. Dampilova in 2012. (Khankh, Khövsgöl Province, Mongolia). (In Bur.)

Жамцарано. АВ ИВР РАН - Жамцарано Ц. Ж. Материалы по шаманству // Архив востоковедов Института восточных рукописей РАН (АВ ИВР РАН). Ф. 62. ОП. 1. Ед. хр. 15. Л. 19.

Ксенофонтов. Якутский филиал СО РАН - Kceнофонтов Г. В. О бурятах. Хориин хоёр заян // Якутский филиал СО РАН. Ф. 4. Оп. 1. Ед. хр. 52а. Л. 160.

for Mongolian, Buddhist and Tibetan Studies, Siberian Branch of the RAS. Coll. 36. Cat. 1. File 1187. (In Russ.) 
Baldaev S. P. Zurag Boro Sharga. Walking-Sticks of Shamans. 1942. At: Center for Oriental Manuscripts and Xylographs, Institute for Mongolian, Buddhist and Tibetan Studies, Siberian Branch of the RAS. Coll. 36. Cat. 1. File 1046. (In Bur. and Russ.)

Jamtsarano Ts. J. Materials on Shamanism. At: Ar-

\section{Литература}

Бадмаев 2019 - Бадмаев $A$. A. Образ змеи в традиционной культуре бурят // Зеркало культур: памяти А. М. Сагалаева / сост., предисл. К. А. Сагалаев; отв. ред.: А. П. Деревянко, А. Х. Элерт. Новосибирск: Изд-во ИАЭТ СО PAH, 2019. C. 118-126.

Басангова 2019 - Басангова Т. Г. Животные в калмыцком фольклоре. Элиста: Изд-во КалмГУ, 2019. 192 с.

Бурнаков 2020 - Бурнаков В. А. Змеиные сюжеты в хакасском фольклоре // Томский журнал лингвистических и антропологических исследований. 2020. № 1(27). С. 90-100. DOI: 10.23951/2307-6119-2020-1-90-100

Вульф 2008 - Вульф К. Антропология: История, культура, философия / пер. с нем. Г. Хайдаровой. СПб.: Изд-во С.-Петерб. ун-та, 2008. $280 \mathrm{c.}$

Дампилова 2017 - Дампилова Л. С. Мифологическая семантика змей (могой), хозяев вод $(л y c)$ и дракона (луу) в фольклоре монгольских народов // Традиционная культура. 2017. № 4. С. 182-189.

Затопляев 1890 - Затопляев Н. И. Зуруктун-онгон // Шаманские поверья инородцев Восточной Сибири. Иркутск: Тип. К. І. Витковской, 1890. С. 1-10.

Манжигеев 1978 - Манжигеев И. А. Бурятские шаманистические и дошаманистические термины. М.: Наука, 1978. 125 с.

\section{References}

Badmaev A. A. The image of the snake in Buryat traditional culture. In: Sagalaev K. A. (comp.), Derevyanko A. P., Elert A. Kh. (eds.) The Mirror of Cultures. Commemorating Prof. A. Sagalaev. K. Sagalaev (foreword). Novosibirsk: Institute of Archaeology and Ethnography (Siberian Branch of RAS), 2019. Pp. 118-126. (In Russ.)

Basangova T. G. Animals in Kalmyk Folklore. Elista: Kalmyk State University, 2019. 192 p. (In Russ.)

Burnakov V. A. 'Snake motives' in Khakas folklore. Tomsk Journal of Linguistics and Anthropology. chive of Orientalists, Institute of Oriental Manuscripts of the RAS. Coll. 62. Cat. 1. Item 15. P. 19. (In Russ.)

Ksenofontov G. V. About Buryats: Khoriin Khoer Zayan. At: Yakutsk Scientific Center, Siberian Branch of the RAS. Coll. 4. Cat. 1. Item 52a. P. 160. (In Russ.)

Нанзатов, Содномпилова 2005 - Нанзатов Б. З., Содномпилова М. М. Байтог: «Баруун буураһууд». Исследование локальной группы бурят // Народы и культуры Сибири. Взаимодействие как фактор формирования и развития. Вып. 4. Иркутск: МИОН, 2005. С. 47-54.

Окладников 1980 - Окладников А. П. Петроглифы Центральной Азии. Л.: Наука, ЛО, 1980. 272 c.

Потанин 1883 - Потанин Г. Н. Очерки Северо-Западной Монголии. Вып. IV. Материалы этнографические. СПб.: Тип. Киршбаума, 1883.1026 c

Пропп 2009 - Пропn В. Я. Исторические корни волшебной сказки. М.: Лабиринт, 2009. $332 \mathrm{c}$.

Санжеев 1931 - Санжеев Г. Д. Дархатский говор и фольклор. Л.: Изд-во АН СССР, 1931. $12 \mathrm{c}$.

Цивьян 1984 - Цивьян Т. В. Змея = птица: к истолкованию тождества // Фольклор и этнография. У этнографических истоков фольклорных сюжетов и образов. Л.: Наука, 1984. C. 47-57.

Хангалов 2004 - Хангалов М. Н. Собр. соч.: в 3 т. Т. III. Улан-Удэ: Респ. тип., 2004. 312 с. Ринчен 2013 - Ринчен Б. Монгол бөөгийн дуудалга (= Призывания монгольских шаманов). Улаанбаатар: Удам соёл ХХК, 2013. $300 \mathrm{c.}$.

2020. No. 1(27). Pp. 90-100. (In Russ.) DOI: 10.23951/2307-6119-2020-1-90-100

Dampilova L. S. Mythological semantics of snakes (mogoy), water spirits (luz) and dragon (luu) in the folklore of the Mongolian peoples. Traditional Culture. 2017. No. 4. Pp. 182-189. (In Russ.)

Khangalov M. N. Collected Works. In 3 vols. Vol. III. Ulan-Ude: Respublikanskaya Tipografiya, 2004. 312 p. (In Russ.)

Manzhigeev I. A. Buryat Shamanic and PreShamanic Terms. Moscow: Nauka, 1978. 125 p. (In Russ.) 
Nanzatov B. Z., Sodnompilova M. M. Baitog: 'Baruun buurahuud'. Investigation of local group of Buryats. In: Turov M. G., Kononova T. N. (eds.) Peoples and Cultures of Siberia. Interaction as a Formation and Development Factor. Irkutsk: Irkutsk Interregional Institute of Social Sciences, 2005. Vol. 4. Pp. 47-54. (In Russ.)

Okladnikov A. P. Petroglyphs of Central Asia. Leningrad: Nauka, 1980. 272 p. (In Russ.)

Potanin G. N. Essays on Northwestern Mongolia. Vol. IV: Ethnographic Materials. St. Petersburg: Kirschbaum, 1883. 1026 p. (In Russ.)

Propp V. Ya. Historical Roots of the Wonder Tale. Moscow: Labirint, 2009. 332 p. (In Russ.)

Rinchen B. Mongolian Shamans: Invocation Texts. Ulaanbaatar: Udam Soel, 2013. 300 p. (In Mong.)
Sanzheev G. D. The Darkhad: Language and Folklore. Leningrad: USSR Academy of Sciences, 1931. 12 p. (In Russ.)

Tsivyan T. V. Snake = bird: the equivalence interpreted. In: Putilov B. N. (ed.) Folklore and Ethnography. At the Ethnographic Origins of Folklore Plots and Images. Leningrad: Nauka, 1984. Pp. 47-57. (In Russ.)

Wulf Ch. Anthropology. Philosophy, History, Culture. G. Khaydarova (transl.). St. Petersburg: St. Petersburg University Press, 2008. 280 p. (In Russ.)

Zatoplyaev N. I. Zuruktun-ongon. In: Non-Russian Populations of Eastern Siberia and Their Shamanic Beliefs. Collected Papers. Irkutsk: K. Vitkovskaya, 1890. Pp. 1-10. (In Russ.) 